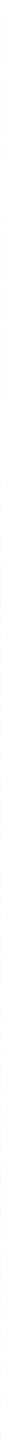

The Otago Farmers Market Photo: Liz Sinclair

My favourite farmers' market in Aotearoa is in Dunedin.

Over the warmer months it has the best fresh produce in

New Zealand: Central Otago apricots the size of peaches, oldschool gooseberries, greengage plums. But the Otago Farmers Market also offers a physical pun. It's at Dunedin's famous Railway Station, and there on the station platform you'll also find many artisan products, like seaweed condiments, craft beer, and bread of every kind. A 'platform', according to Choudary and Parker, is 'a business model that uses technology to connect people, organisations and resources in ecosystems to exchange goods, services and ideas' (Choudary and Parker, 2016). Take a broad view of 'technology' and the Otago Farmers Market is a platform on a platform.

Kevin Jenkins is Managing Director of professional services firm MartinJenkins, a Director of the digital automation firm Quanton, and Chair of the School of Government Advisory Board at Victoria University of Wellington.

\section{Digital platforms}

Talk of 'platforms' - or the 'sharing economy' - sometimes seems to be ubiquitous. But how significant is this model, and what kinds of policy and regulatory issues is it raising?

As Facebook, Amazon, Ali Baba, Tencent, Uber and so on have grown to dominance over the last decade, these huge digital marketplaces have become the face of the model. However, the repeated citing of just this small group of behemoths has obscured the true depth and breadth of the platform phenomenon, and also the pace of change. The model is expanding and innovating quickly, and much of this is at smaller, local scales.

With the focus on the big international players, it's easy to overlook the fact that this model is becoming pervasive here in New Zealand. The collective benefits these local platforms will provide will be enormous, making the lives of $\mathrm{New}$ 
Zealanders better. But, as throughout the world, there are also significant policy and regulatory challenges that need to be worked through.

\section{How we talk about digital platforms}

The language we use to describe digital platforms is not yet settled, and this matters because it in part reflects different perspectives and interests, as Kenney and Zysman have pointed out. 'Platforms' is the term used by more academic commentators, but common parlance generally favours 'the sharing economy', which suggests something more unambiguously benign. Kenney and Zysman write: 'Its boosters have called it the Creative Economy or the Sharing Economy, whereas those less convinced of its beneficence have dubbed it the Gig Economy or the Precariat'. They point out that Facebook is not based on 'sharing', but rather on monetising human effort and consumer assets, and they link this to some key policy and regulatory challenges: 'the advantage of platformbased companies often rests on an arbitrage between the practices adopted by platform firms and the rules by which established companies operate, which are intended to protect customers, communities, workers, and markets' (Kenney and Zysman, 2016, p.62).

Rob Stock argues that calling platforms 'the sharing economy' is misleading, because very few of the people involved are actually sharing anything. Rather, platforms are about 'good, old-fashioned deals being done between asset owner, and asset hirer'. Using New Zealand-based platforms as examples, he breaks down those involved into 'sharing opportunists' (generating extra income from an existing asset, like renting out a motorhome on Mighway); those driven by economic necessity (renting out a room on LookAfterMe, an Airbnb-like platform for mature women); and, finally, those involved for purely commercial reasons (buying a car specifically to rent it out on Yourdrive) (Stock, 2017).

\section{The power of the platform}

It seems that successful platforms have three key characteristics (Choudary and Parker, 2016). First, they enable exchange of value between producers and consumers (the 'why'), often with added value through an algorithm (so that users receive only the most valuable information). Second (the 'how'), they enable a great user experience when attracting, facilitating and matching transactions. The third characteristic is the layering of new interactions (Uber Eats is a recent New Zealand example).

Choudary and Parker use the Uber example to explain why platforms are so powerful:they eliminate gatekeepers, unlock new supply and demand and create community feedback loops. Uber, for example, performs a matching service that serves as a virtuous cycle. More demand is met by more opportunistic drivers, which increases geographic coverage, which adds that platforms 'enable scale by allowing others to generate profits in the "long tail" of the distribution curve avoiding diminishing returns associated with traditional (linear) value chain models'. They also enable asymmetric growth and competition by 'driving the demand of a core market through complementary markets, which are often subsidized (or free) to users and which cross industry lines' (Accenture, 2016).

Parker and Van Alstyne (2016) argue that platforms invert companies, transforming their traditional focus on internal value creation to an outward focus on external value creation. They also note that their use of assets that they don't own allows them to grow much faster than traditional firms.

\section{A 2016 report by global technology firm Accenture adds that platforms "enable scale by allowing others to generate profits in the "Iong tail" of the distribution curve - avoiding diminishing returns associated with traditional (linear) value chain models'.}

leads to faster pickups, which encourages more customers to join the platform and more people to sign up as drivers. Driver downtime is lowered and so are prices, which leads to more scale. (ibid.)

They also note that this network effect is different from that of the 20th-century industrial era, which was primarily about monopolies based on supply economies of scale. Digital platforms, by contrast, enable the possibility of monopolies based on demand economies of scale.

A 2011 collection of essays on platform economics suggests that two-sided platforms arise where there are externalities and where there are transaction costs that otherwise prevent the two sides solving the externality directly (Evans, 2011). A 2016 report by global technology firm Accenture

\section{Non-profit and cooperative platforms}

But not all platforms are about making money for their owners. There is also a less visible world made up of 'many platforms that have created massive value, but have never made a profit, and don't even strive to make money - on purpose' (Evans and Schmalensee, 2016, p.2). Both MasterCard (starting in 1966) and Visa (in 1971) were not-for-profit membership associations that charged just enough to cover costs, until they were IPO-ed into profit-making in the 2000s.

Many other multi-sided platforms haven't made the leap to profit. Standardsetting organisations (SSOs) help members agree on standards and publish them at low cost, or even free. These include those relating to mobile carriers, handset makers and chip providers. Evans and Schmalensee claim there are almost 1,000 SSOs, and that SSOs 
Figure 1: Ranking by number of companies

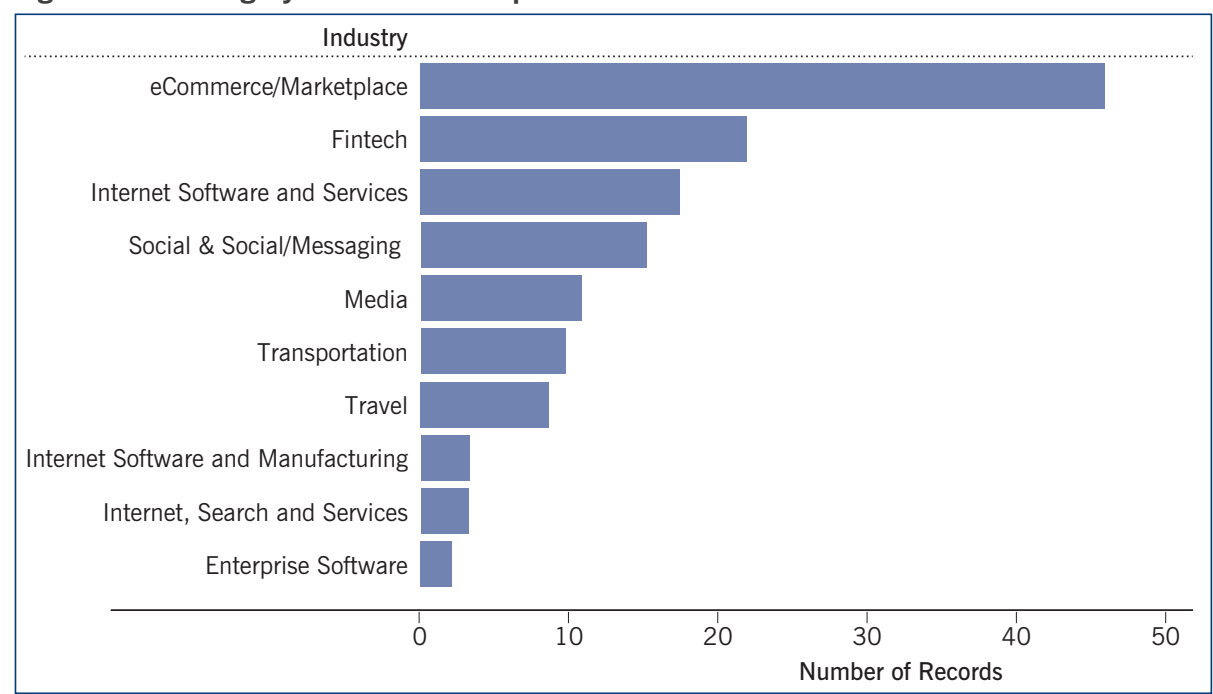

Source: Evans and Gawer, 2016, p.17.

Figure 2: Ranking by market value

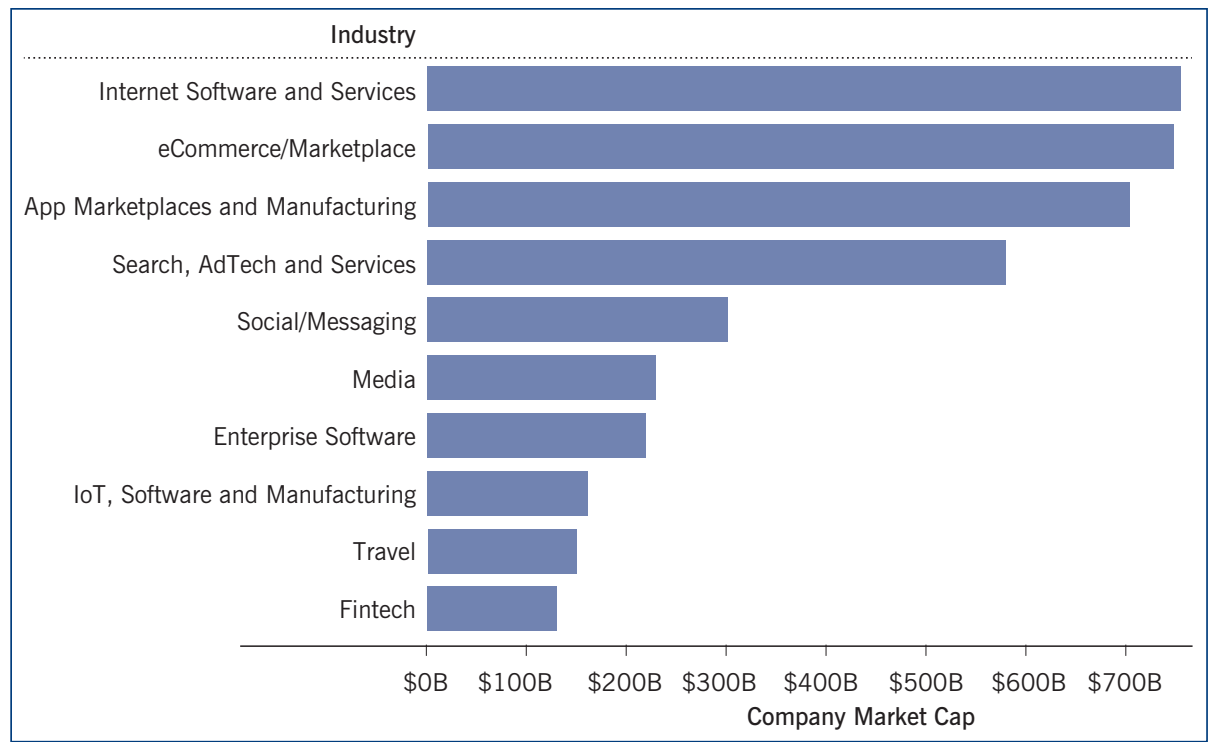

Source: Evans and Gawer, 2016, p.17.

published more than 200,000 standards between 1975 and 2011. A recent study also found that these platforms were responsible for'a significant amount of economic growth in the last several decades' (ibid.). Certainly, both Apple's iOS and Google's Android are only possible because of SSO-created standards.

In response to 'death star platforms' like Airbnb, so called for their pursuit of world domination, we have also been seeing the rise of platform cooperatives (Johnson, 2016). One example is Fairmondo, a co-operative version of eBay founded in Germany.

Despite all this, one recent article notes that platforms 'are still being underestimated. Incumbents and business management literature title them as modern "middlemen", not recognising the value-add' (Uenlue, 2017, p.1).

The growing dominance of the big platforms The first global survey of platform companies valued at US\$1 billion or more identified 176 large platform companies, valued collectively at over US $\$ 4.3$ trillion (Evans and Gawer, 2016). The survey report divided these companies into four categories. There were 160 transaction platforms (social media, marketplaces, media, music, finance and gaming); five innovation platforms (software firms like Salesforce which 'derive much of their value and innovation from co-creating products and services'(p.14)); six integrated platforms (which, like Apple, for example, combine double-sided markets with manufacturing supply chains); and five investment platforms (like Softbank, which isn't a platform as such, but has invested in Yahoo! Japan, Ali Baba, Housing.com in India and others).

Evans and Gawer investigated which sectors the platform firms were most active in, and found that ranking sectors by the number of platforms in each one revealed a different pattern than ranking by market value. (Evans and Gawer, 2016, p.17)

This first international survey discovered that there are some sectors where platforms are yet to make much headway. Despite there being hundreds of workplace platforms like TaskRabbit, which match demand for tasks with individuals and their skills, none has got close to a US\$1 billion valuation. Evans and Gawer wondered if inherent fragmentation by type of work and by geography may have caused lack of scaling' (ibid., p.17). The healthcare sector is another example. On the other hand, the lack of progress in those sectors may simply be a case of 'watch this space'.

A number of traditional firms are now striving to add platforms (ibid.). Daimler, for example, bought RideScout, a US transaction platform that aggregates transportation and parking options in real time, and MyTaxi, a German ridesourcing platform akin to Uber. Time will tell how successful the traditional firms will be at disrupting themselves, but many of the commentators on disruptive technologies are backing the new entrants. On the other hand, Bughin, Catlin, Hirt and Willmot distinguish between incumbents that move boldly and those which don't:

Incumbents moving boldly command a 20 percent share, on average, of digitizing markets. That compares with only 5 percent for digital natives on the prowl...we found that revved-up incumbents create as much risk to the revenues of traditional players as attackers do. And it's often incumbents' moves that push an industry to the tipping point. That's when the ranks of slow movers get exposed to life-threatening competition. 
The Accenture report mentioned above cited a prediction that by 2018 more than half of large enterprises will either create or partner with platforms. It claims that $25 \%$ of the world's economy will be digital by 2020 (compared with 15\% in 2006), and with platforms representing a fast-growing proportion of that. It adds:

Largely driven by platform strategies, there are more than 140 'unicorns' with a total valuation of more than [US]\$500 billion - 'unicorns' are startups with valuations of $\$ 1$ billion or more based on fundraising. Within five years, a core component of corporate valuations and capital markets will be based on their platform ecosystems and digital assets. (Accenture, 2016, p.38)

\section{Platforms are outpacing policy and regulation}

The rise of the platforms is important for public policy for several reasons. The digital economy is becoming a dominant part of the world economy, and the new platforms are on the way to becoming the dominant business model in the digital economy. The new model has created a plethora of new or radically changed marketplaces that are disrupting current rules and demanding new ones. As well as crossing technologies, they are disintermediating markets and adding value to both sides: this has significant implications for officials who are assessing relevant benefits between suppliers and customers in order to determine whether there is a need to intervene and, if so, how to intervene.

The platform phenomenon also raises issues for the current machinery of government. Most policy advice is generated by sector agencies, and those agencies have already been grappling for some time with how to shift from silos to successful cross-agency work. The new digital platforms are reinforcing the need for new multi-sector approaches.

Much legislation and regulation predates the digital world, and is difficult to apply or enforce in this new context. Kenney and Zysman talk about how the rise of platforms is challenging current policies and regulations. A local example is Uber's arrival in New Zealand, which sparked a high-profile public debate about regulation of the ride-sourcing industry, leading to eventual changes to legislation. Victoria University law professor Gordon Anderson also remarked recently that New Zealand's current employment law is ill-equipped to cope with the new 'gig' economy: 'You can't use a mid-20th century legal structure to deal with a whole new mode of employment' (Harris, 2017).

Kenney and Zysman go further than this, though, arguing that, as many have suspected:

Platform entrepreneurs increasingly believe that if they possess a firstmover advantage, they can, in fact, remake existing law by creating new regulated industries like taxis and hotels (Kenney and Zysman, 2016). Berlin is an example of a city that has restricted Airbnb, not to protect the traditional hospitality sector (e.g. hotels), but to preserve supply in another sector - that is, residential rentals. In New Zealand, Queenstown is doing the same. Interestingly, Airbnb's own data shows no diminution in Airbnb supply in Berlin, indicating that the restriction may have had little effect there (Morris, 2016), although arguably this is simply a matter of time. Kenney and Zysman also cite the European Commission's taking on of US platforms around anti-trust policy, and the clashes between ICT firms and platforms around intellectual property. They also point to

\section{Another challenge is that network effects mean that platforms often grow exponentially, with this pattern only being noticed when scale is achieved and, again, 'facts' have changed.}

practices on their platforms that essentially establish new norms of behavior. It is often said in Silicon Valley, 'Don't ask permission; ask for forgiveness' ... The code writers, taking Uber as an example, have already reshaped social behavior. Government rules will influence how the new technologies are deployed and their consequences, but in a platform economy, government decisions may be constrained by the 'facts' in the software. (Kenney and Zysman, 2016, p.67)

Governments often welcome the rise of platforms as a way of spurring innovation and improving productivity through better utilisation of assets (Evans and Gawer, 2016). On the other hand, they also realise that platforms present challenges across a range of policy issues, including labour, tax, competition, use of data and privacy.

Some platforms are creating piecework 'jobs' outside the ambit of traditional employment law, and others are disrupting issues raised about network policy driven by clashes between traditional carriers and platforms, such as some US carriers blocking advertisements on smartphones. Policy-makers and regulators are scrambling to keep up.

Under the broader heading of 'digital trust', the 2016 Accenture report raised the issue of data ethics, encompassing ethical questions going beyond simply privacy such as who owns data, who can use it and who can access it.

\section{How might policymakers and regulators respond?}

Policymakers and regulators face some big challenges. The usual approach of identifying issues first is made more difficult by the nature and speed of innovation. A feature of disruptive technologies is that they are not always easy to identify early on, because they often emerge from a different industry: for example, an online site from the world of ICT allowing TradeMe to displace printed 'trade and exchange' publications. 
Policymakers and regulators need to find the right lens or lenses to give a coherent picture of what's happening. Looking at issues through an historical regulatory lens immediately raises the question of which regulatory regime should apply, or whether a new sector has emerged that requires a new regime.

Another common default is to look at issues through the lens of specific technologies, such as artificial intelligence or smart devices. However, that has the risk of being too narrow, because many platforms integrate different technologies. A technology lens also carries the risk that many innovators themselves may not fully understand the implications of the technologies they are driving, let alone the conditions of human social existence ... this presupposes a regulatory environment that supports the development, application and exploitation of technologies that will contribute to such an overarching purpose, an environment properly geared for risk management and benefit sharing.

They list four key challenges for regulators:

Relative to such a project, regulators are liable to be called to account if:

1. they fail to take sensible precautionary measures relative to the risks presented by emerging technologies;

\section{... traditional regulatory model of policy development and review cannot cope with the rapid-fire disruptive change we are seeing, the familiar model risks simply being too slow.}

policymakers and regulators. Further, by the time they do grasp the implications, further 'layers' may have been added and other 'facts on the ground' may have emerged.

Another challenge is that network effects mean that platforms often grow exponentially, with this pattern only being noticed when scale is achieved and, again, 'facts' have changed. Some of these regulatory challenges - including speed of change and the need for a wide-angled lens - were explored recently in this journal in a discussion of 'regulatory stewardship' as involving 'a whole-of-system view, and a proactive, collaborative approach to the care of the regulatory system(s) within which an agency works' (Winson, 2017, p.3, citing New Zealand Government, 2017).

The Cambridge Core website summarises some key points made by Brownsword and Goodwin:

If law and technology are to work together to improve the basic
2. the purposes or objectives that they are pursuing (or, the manner and means by which they pursue those objectives) are judged to be illegitimate;

3. their interventions are ineffective and not fully fit for purpose; or

4. they have failed to make an initial targeted and sustainable regulatory connection; or, where regulation has become disconnected, they have failed to make an appropriate reconnection. (Brownsword and Goodwin, 2012)

Policymakers and regulators in Aotearoa face the challenge of truly understanding the business models underpinning the emergent platform firms, both globally and domestically, as they are evolving at pace and growing exponentially, as well as blurring the lines between sectors and driving the emergence of whole new sectors.
Platforms in Aotearoa: origins and recent developments

TradeMe was an early New Zealand platform, established in 1999, quickly followed by Bookabach in 2000, Holiday Houses in 2003 and Holiday Homes in 2004 (Charity, 2015). Since then, local platforms have started to emerge exponentially. None may have hit the US\$1 billion benchmark yet, although some have faith in accounting platform Xero, but there are many in the race.

Transport is a fertile area here. MyCarYourRental matches people wanting to rent a car with people overseas who have parked their car at Auckland Airport: instead of paying for parking, the travellers can make cash. YourDrive matches people seeking cars for casual rental with car owners seeking to share their cars when they don't need them. Transfervans describe themselves as an 'Uber style delivery service for over-sized items', matching customers with van or truck owners and focusing on the 'last mile delivery network'. Zoomy is a local competitor to Uber in the related ridesourcing sector.

There are also lots of new local financial services platforms, such as Sharesies, which allows people to invest $\$ 50$ in the same options as people investing \$5,000, and Harmoney, selfdescribed as a 'peer-to-peer money marketplace'. The Financial Markets Authority listed eight crowdfunding services in New Zealand in November 2017: two examples are Snowball Effect, for investing and capital raising, and selfdescribed as a 'curated marketplace which simplifies access to a range of investment opportunities', and PledgeMe, which has funded commercial and other initiatives, including some that are both (like Eat My Lunch).

In fact, local platforms are multiplying everywhere. Boosted 365 is 'here to remove every possible barrier between artists and backers', and has funded a Māori trading card game, an annual arts and theatre event for shoe lovers, and more. Shuttlerock, a software content marketing platform, became a 'layer' on Facebook's global platform when they became one of 15 Facebook partners globally. Housesitters and Kiwihousesitters compete in the 
house- and pet-sitting market, while Sharedspace does the same for commercial space. Platforms for platforms are emerging too: there are now 'collaborative economy meetups' in Auckland - organised via an online platform - that are designed for people to share how to share.

\section{Parkable and Campable: home-grown} disruptive platforms

It is worth looking at a couple of local platforms more closely. Parkable is an excellent example of a home-grown appbased disruptive transaction platform that displays Choudary and Parker's three characteristics of successful platforms.

Parkable addresses the difficulty in finding a car park in our cities, where a third of congested downtown traffic is simply looking for parking (Barter, 2013). The Parkable app matches demand with supply (reported 'live' via an Internet of Things network of sensors), creating value for both - the first characteristic of success. The original idea was to access - or 'share' - unused parking spaces for events, such as residential driveways near Eden Park during big rugby games. This is still part of the business, but Parkable has found that higher-frequency demand embeds habits faster, and it now focuses on daily employee parking. One key innovation has been on the supply side, with most of the over 4,000 places they manage in Auckland being non-traditional parking areas such as underutilised church, supermarket and school parking lots, vacant lots, and areas that are between tenancies.

Thousands of drivers are now using the app. It is growing fast both in Auckland and in other cities. This demonstrates the second characteristic - a great user experience when attracting, facilitating and matching transactions.

Things really get interesting, though, when we look at how Parkable is layering new interactions, the last of the three key characteristics. As it learns from how people behave on both sides of the platform, Parkable is innovating furiously. One fast-growing example is Parkable for Business, which manages excess demand and underutilised supply of parking spaces within an organisation. One of the platform's clients allocates its best corporate parks to its senior executives, who often don't use them; other corporate parks are available for long-term or casual renting to firm employees. Parkable has enabled an internal day market for those parks. Different payment regimes can apply (for example, who gets the payment and at what price). This enterprise approach has multiple benefits, including less demand on the city's overall parking supply, easier access to parks for all employees, and cash benefits to either the 'park owner' or the firm. Another value created is that clients can include a visitor car park when they send meeting invitations.

Brody Nelson, the founder of Parkable, also launched Campable, which matches motorhomes with private land. It solves the problem of excess demand for traditional motorhome parks by adding private land to the supply, and it also eases the freedom camper problem. There is much debate in Wellington about freedom campers congesting and even befouling the south coast, because of the limited space and toilet facilities. Campable allows a visitor to find a local person willing to let them park in their driveway - and perhaps use some of their facilities - for a fee.

So Campable adds value to both sides, and its growing business shows that it is offering a good experience. It also tantalises with the prospect of spreading economic benefits wider with what it calls 'microtourism'. We know that authentic experiences are the new 'tourism gold', and making it easy for tourists to spend a night on a lifestyle block off the usual tourist paths, and to meet working locals and consume locally made product, is very attractive.

\section{A mash-up of platforms to address} accommodation and transport issues

A second layer of the rise of platforms locally, and a perfect illustration of how descriptors are not keeping pace with the real world, is a mash-up of platforms currently taking physical form in one fastgrowing New Zealand centre. A shortage of worker accommodation there is exacerbated by limited public transport and increasing traffic congestion. A developer is planning a new build of 300 apartments (many already pre-sold to employers for worker accommodation), with several platforms

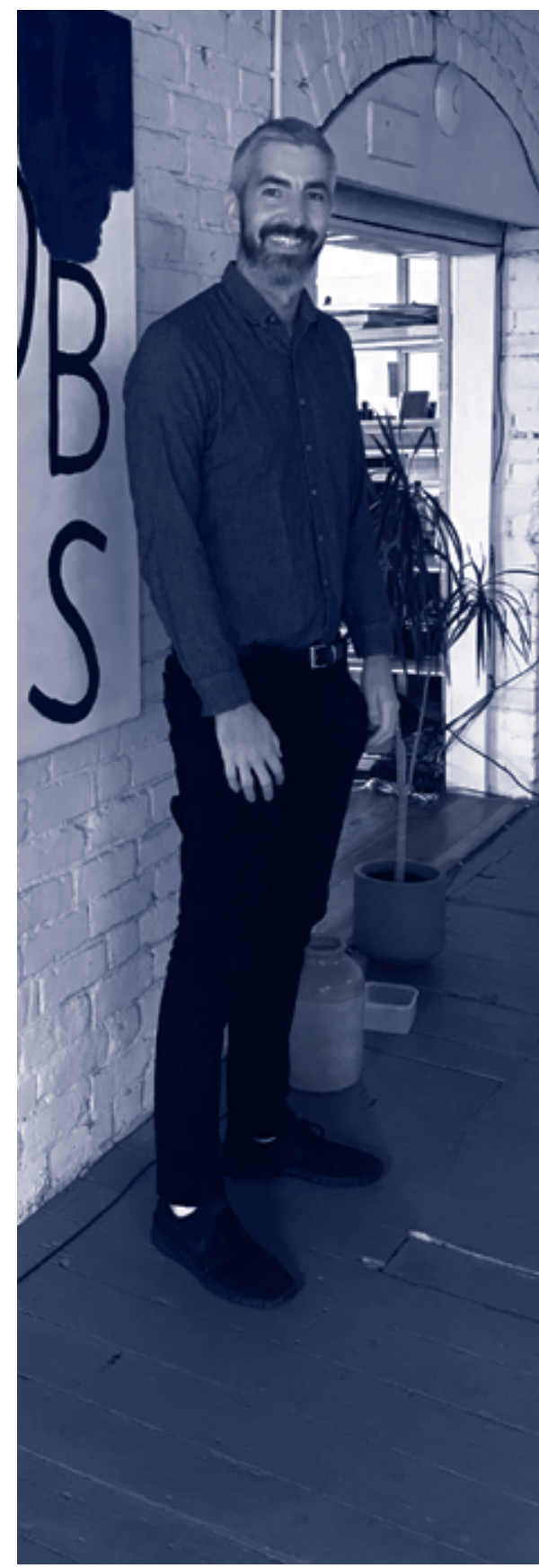

Brody Nelson, founder of Parkable and Campable

integral to the design. Each apartment will have its own bedrooms and bathroom, but other facilities will be shared, such as cooking, lounge and laundry. This reflects a trend in places like New York called 'coliving', or a 'disruptive alternative to the way people live' - one example is WeLive's 200unit fully furnished and fully serviced site at 110 Wall Street, Manhattan (Winston, 2016).

The New Zealand concept does not stop there though. Parkable will manage its car parks, cars for casual use will be provided by a car-sharing platform, and the facility will run buses with bookings online. 


\section{The regulatory challenge in Aotearoa}

So far, so exciting. However, both Parkable and Campable run the risk of getting ahead of existing laws and regulations. Two districts have banned Campable, seemingly because of fears of negative impacts on local motorhome parks (akin to cities looking to ban Airbnb due to fears of a negative impact on local hotels and motels).

Another obstacle is the CampingGrounds Regulations 1985, which were issued before mobile telephony and the internet. The regulations require landowners to obtain a resource consent before they can have more than one motorhome stay on their land, but local authorities can issue exemptions.

The motives for regulation in this area are obvious: to ensure appropriate capacity and environmental management, and to set health and safety standards. Again, though, the facts are getting in the way. Freedom camping is arguably a response to lack of supply in the right places. Further, Campable displays the second characteristic of good platforms: that is, it uses algorithms to provide valuable information to all sides. Drivers can access real-time amenity and capacity data and feedback from others about their experience. Landowners can access feedback about drivers. Regulators can access data about usage, feedback from both sides and so on. In other words, Campable offers a different way of meeting the objectives of the regulations, and one that provides a lot more data about compliance.

We are no different from the rest of the world: 'The current New Zealand regulatory framework does not provide effective regulations for apps such as Uber and Airbnb' (Henderson, 2016, p.5).

\section{A more responsive regulatory model for the platform era}

Experience of the platform era so far seems to be telling us that the traditional regulatory model of policy development and review cannot cope with the rapid-fire disruptive change we are seeing: the familiar model risks simply being too slow.

A major part of the problem is getting timely intelligence about new business models and new technologies. Traditionally, our officials have had a deep understanding of the particular industry they create policy for and regulate; but in our new world of cross-discipline, crosstechnology platforms, New Zealand's policymakers and regulators are grappling with the problem that disruption to their industry may well come from outside it. They therefore also need to be aware of what's happening outside their industry and beyond its traditional technologies.

Armed with better intelligence, officials then need to be able to apply a new, higher level of forecasting capability. By getting more intelligence earlier, then responding to it quickly and effectively, officials will be able to aspire to something approaching 'real-time' regulatory change.

This is a massive challenge, but New Zealand officials do have one advantage here: the opportunity to learn from overseas experience. We are certainly not trailing the international field, but there are some frontrunners whose regulatory responses we can dissect and learn from, whether in competition law or property rights or other fields. Developing new regulatory models in Aotearoa for the age of the platform will depend on us successfully applying lessons from abroad.

\section{Conclusion}

Back on the platform at my favourite local farmers' market, Dunedinites are connecting, sharing and exchanging including talk and ideas, not just berries from the Taieri Plains - but doing it in their largely pre-digital ways (there's a bit of EFTPOS). In parallel, though, many of the products are also being sold online, and
- naturally - a new New Zealand platform was launched in November 2017. It's called Ooooby, and its website notes: 'We deliver fresh fruit and vegetables from local and organic growers to you every week. It's like food delivery from a farmers market.' That kind of local dynamism is driving much of the growth and innovation among digital platforms, beyond the big, oft-cited players like Facebook and Amazon.

Here in Aotearoa, the digital platform phenomenon is as pervasive - and as fluid and exciting - as anywhere else. As around the world, our policymakers and regulators are reckoning with the quickening pace and unpredictability of the phenomenon, with its tendency to go off in quite unexpected directions. Platforms have been getting ahead of the curve, raising complex issues in regulatory areas such as tax, employment, health and safety, consumers and competition. Those who make and enforce policy in this country have the critical job of managing and influencing that growth, through providing a regulatory framework that will allow the considerable promise of platforms in economic and social benefits to be realised.

\section{Acknowledgements}

The author thanks Girol Karacaoglu, Liz Sinclair, Bill Moran, Hanna Tevita, Brody Nelson and Jonathan Boston for their insightful comments on a draft of this article, which led to a number of improvements.

\section{References}

Accenture (2016) Accenture Technology Vision 2016: people first: the primacy of people in a digital age, Accenture

Barter, P. (2013) 'Is 30\% of traffic really searching for parking?', www. reinventingparking.org, 7 October

Brownsword, R. and M. Goodwin (2012) Law and the Technologies of the Twenty-first Century: text and materials, Cambridge; New York: Cambridge University Press
Bughin, J., T. Catlin, M. Hirt and P. Willmot (2018) 'Why digital strategies fail', McKinsey \& Company, January https://www.mckinsey.com/businessfunctions/digital-mckinsey/our-insights/why-digital-strategies-fail

Charity, J. (2015) 'Peer-to-Peer: the sharing economy in New Zealand', Management Magazine, April

Choudary, S.P. and G. Parker (2016) 'How to build a successful platform business', INSEAD Entrepreneurship blog, 3 June, https://knowledge. 
insead.edu/blog/insead-blog/how-to-build-a-successful-platformbusiness- 4728

Evans, D.S. (2011) Platform Economics: essays on multi-sided businesses, Competition Policy International

Evans, D.S. and R. Schmalensee (2016) 'Some of the most successful platforms are ones you've never heard of', Harvard Business Review, 28 March

Evans, P.C. and A. Gawer (2016) The Rise of the Platform Enterprise: a global survey, Emerging Platform Economy series, 1, New York: Center for Global Enterprise

Harris, C. (2017) 'NZ law ill-prepared for gig economy, professor says', Stuff, 26 November, https://www.stuff.co.nz/business/ industries/99140479/nz-law-illprepared-for-gig-economy-professorsays, accessed 29 November

Henderson, L. (2016) 'Innovators or rule breakers? Regulating Uber, Airbnb and the sharing economy', LLB dissertation, University of Otago Johnson, C. (2016) '11 platform cooperatives creating a real sharing economy', www.shareable.netblog, 18 May
Kenney, M. and J. Zysman (2016) 'The rise of the platform economy', Issues in Science and Technology, 32 (3), Spring, pp.61-9

Morris, D. (2016) 'Banning Airbnb hasn't had much impact in Berlin yet', fortune.com, 4 December

New Zealand Government (2017) Government Expectations for Good Regulatory Practice, Wellington: New Zealand Government, http:// www.treasury.govt.nz/regulation/informationreleases/pdfs/good-regpractice.pdf, accessed 29 November

Parker, G. and M. Van Alstyne (2016) 'How digital platforms are revolutionizing markets', Platform Economics, 7 April

Stock, R. (2017) 'The share club', Dominion Post, 8 November

Uenlue, M. (2017) 'Platform business model (part 2): fundamental principles', http://www.innovationtactics.com, 11 April

Winson, S. (2017) 'Regulatory stewardship: voice of the regulator', Policy Quarterly, 13 (4), pp.3-9

Winston, A. (2016) 'Co-working company WeWork unveils its first co-living apartments in New York', dezeen.com, 6 April

\section{Master of e-Government BETTER GOVERNMENT THROUGH TECHNOLOGY}

Gain the knowledge and competence to understand, analyse, design and manage transformational e-government initiatives.

Connect with experts and a global community of classmates

Your courses are designed by experts in government and ICT and taught by leading academics. Be part of a school that attracts not only local professionals but a talented group of international students.

\section{FURTHER \\ INFORMATION:}

Academic enquiries

ø verna.smith@vuw.ac.nz

Enrolment enquiries

ørobyn.mcCallum@vuw.ac.nz

s. 64-4-4636599

\section{TRIMESTER ONE}

EGOV 501 Managing Service Transformation (Core course) The managerial aspect and issues of ICT-enabled service transformation in the public sector.

GOVT 518 Comparative Public Management (Core course) Comparative public management and public policy, with emphasis on contemporary developments in Asia-Pacific and beyond.

$2 \times 15$ point electives from EGOV 500-599, MMIM 500-599, MMPM 500-599, MAPP 500-599

\section{TRIMESTER TWO}

EGOV 502 e-Government, Public Sector Reform and Good Governance (Core course) The theories, principles, models and strategies for using transformational government initiatives to establish good governance, drawing on international and New Zealand experience.

\section{EGOV 520 Introduction to} Research in the Public Sector An introduction to approaches, ethics and methods of doing research in the public sector. This course is co-taught with GOVT 561

MMIM 510 Information Systems Management (Core course) The principles and practices of managing the information systems function within an organisation.

$1 \times 15$ point elective from EGOV 500-599, MMIM 500-599, MMPM 500-599, MAPP 500-599

\section{TRIMESTER THREE}

EGOV 503 Managing ICTenabled Forms of Public Engagement The challenges, conditions and requirements for managing the use of ICTs to achieve effective forms of public engagement.

EGOV 521 Research Project Applications of theoretical, conceptual, analytical, practical and research methodological knowledge to the design and conduct of an applied research project in the area of transformational e-government.

MMIM 513 Managing IT-related Change

The impact of information technology on an organisation and issues concerned with IT related change.

$1 \times 15$ point elective from EGOV 500-599, MMIM 500-599, MMPM 500-599, MAPP 500-599 